\title{
Wax inhibitor performance comparison for waxy crude oil from Fang oilfield
}

\author{
Kreangkrai Maneeintr*, Tanapol Ruengnam, Thodsaporn Taweeaphiradeemanee and Treetasase Tuntitanakij
}

Carbon Capture, Storage and Utilization Research Laboratory, Department of Mining and Petroleum Engineering, Faculty of Engineering, Chulalongkorn University, Bangkok 10330, Thailand.

\begin{abstract}
In petroleum chemistry, waxy oil from paraffins can cause operating problems for oil production. The chemical method is used to remove by using chemicals or additives to prevent the wax problem. In this study, the performance of wax inhibitor are evaluated by the measurement of pour-point reduction and wax deposition of crude oil from Mae Soon area, Fang oilfield. Wax deposition is determined by cold finger technique. Wax inhibitors, hexane, Poly(maleic anhydride-alt-1-octadecene) (PMAO) and monoethanolamine (MEA) are mixed in oil sample at various concentrations. From the experiment, it is presented that hexane is used to reduce pour-point temperature up to $19.55 \%$ and to reduce wax deposit up to $92.56 \%$. Moreover, MEA and PMAO have less effect on pour-point reduction. However, they have high efficiency to prevent wax deposition. PMAO provide the better wax deposition performance than MEA. The amount of wax deposit is lower at the same conditions. The percentage of wax deposit is from $39.19 \%$ to $83.02 \%$ for MEA and from $58.54 \%$ to $88.51 \%$ for PMAO. Furthermore, from the results, the preferred concentration of hexane can be at $10 \%$ and PMAO can be $7500 \mathrm{ppm}$ at low temperature or $5000 \mathrm{ppm}$ for higher temperature. The results of this research can be applied to the practical way for wax deposition prevention operation in Mae Soon area in Fang oilfield to reduce the wax problem in the future.
\end{abstract}

\section{Introduction}

In petroleum chemistry, paraffins can cause waxy crude oil which is a complex mixture of many different components including paraffins, aromatics, resins, asphaltenes and other light hydrocarbons [1-2]. Among these components, the high molecular weight paraffins are responsible for the various problems encountered during production, transportation and storage of waxy crude oils [3]. During the prolonged shut-down of pipeline transporting waxy crude oils, the paraffin crystals form continuously in the oil phase due to the gradual decrease of temperature [4].

Crude oil contains dissolved waxes that can deposit under the appropriate environmental conditions. These can build up in production equipment and pipelines, potentially restricting flow and creating other problems [3]. For wax mitigation and remediation, there are three methods that are commonly used, thermal, mechanical and chemical methods. For this study, the chemical method is choosen due to the continuous oil production operation [5-6]. The chemicals used in this study are hexane, Poly(maleic anhydride-alt-1-octadecene) or ZPMAO. These are the potential chemicals as inhibitors to prevent wax formation [7-8]. Also, monoethanolamine or MEA used as a surfactant to reduce interfacial tension of oil and water can be applied for this study [9].

In addition, Mae Soon area in Fang oil field, Chiangmai, Thailand is the brown field area for petroleum production more than 60 years. Oil from this area contains waxy components and it has many operation problems especially when temperature and conditions change.

Therefore, the main objectives of this study are to compare the performance of 3 wax inhibitors on original crude oil and to investigate the effects temperature and chemical concentration of each inhibitor on wax deposition of original crude oil from Mae Soon at Fang oil field and to measure pour point temperature of oil at various conditions.

This research will investigate the 3 chemical additives that can reduce Mae Soon crude oil pour point temperature or wax deposition. Therefore, the benefits from this project is the performance comparison of wax inhibitors at various conditions in order to select and apply the better inhibitor in the real field at the working conditions in the future.

\section{Materials and methods}

\subsection{Materials}

Waxy crude oil is obtained from Mae Soon area, Fang oilfield in Chaingmai. The physical characteristics of crude oil contain high amount wax which becomes solid 
state in room temperature. The crude oil pour point temperature is $35.3{ }^{\circ} \mathrm{C}$. Hexane with $95 \%$ purity and PMAO with $95 \%$ are purchased from Sigma Aldrich Company. MEA with a purity of $>99.0 \%$ is purchased from Sadara Chemical Company.

\subsection{Experimental procedures}

Pour-point temperature of crude oil is measured following ASTM standard of ASTM D 5853 [10]. First, the test tubes are filled with warm crude oil. Thermocouple is placed in the tube to measure the temperature. The prepared test tubes in the water bath are hold by a lab stand.

For wax dposition prevention test, wax deposition determination is conducted with cold finger technique [11-12]. The test tube is rested in water bath for 3 hours. The experimental temperatures are from $25{ }^{\circ} \mathrm{C}, 35{ }^{\circ} \mathrm{C}$ and $45^{\circ} \mathrm{C}$. The wax inhibitors concentrations are $5 \%, 10 \%$ and $15 \%$ by weight for hexane and 2,500 ppm, 5,000 ppm and 7,500 ppm for MEA and PMAO.

\section{Results and discussion}

\subsection{Effect of Hexane on wax deposition}

In this study, hexane is used as a solvent. It has been investigated the ability on pour-point reduction with varying concentrations from $5-15 \%$. From the result as shown in Figure 1, the pour-point temperatures are $35.3{ }^{\circ} \mathrm{C}, 34.5{ }^{\circ} \mathrm{C}, 29.4{ }^{\circ} \mathrm{C}$ and $28.4{ }^{\circ} \mathrm{C}$ at $0 \%$ or original oil, $5 \%, 10 \%$ and $15 \%$ hexane concentration, respectively. The high rate of reduction is from $5 \%$ to $10 \%$ hexane and the percent reduction can be up to $19.55 \%$ for $15 \%$ hexane concentration compared to original oil.

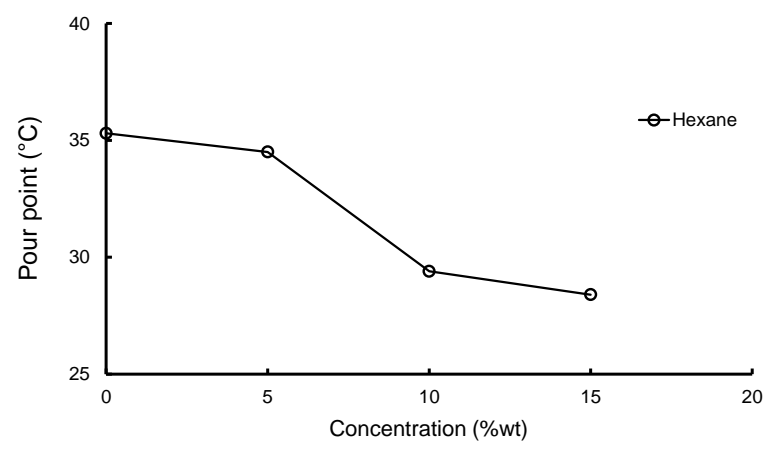

Fig 1. Result of hexane concentration on pour point.

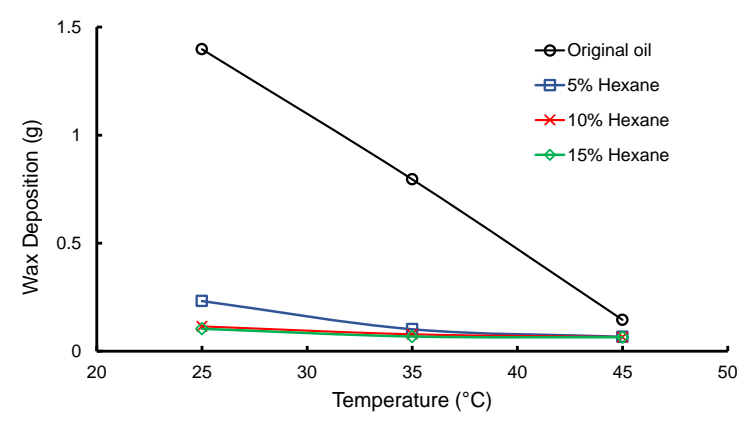

Fig 2. Result of hexane concentration on wax deposition.

For wax deposition of hexane, the experimental temperature is performed from $25{ }^{\circ} \mathrm{C}$ to $45{ }^{\circ} \mathrm{C}$ and the hexane concentration is from $0-15 \%$. As shown in Figure 2, the results present that at $25{ }^{\circ} \mathrm{C}$, the amount of wax has been reduced to $83.38 \%, 91.78 \%$ and $92.56 \%$ for $5 \%, 10 \%$ and $15 \%$ hexane, respectively compared to original oil. Also, at higher temperature like $35^{\circ} \mathrm{C}$ and $45^{\circ} \mathrm{C}$, the amount of wax is lower because wax becomes more liquid and at $45^{\circ} \mathrm{C}$, the amount of wax is at $53.99 \%$, $54.75 \%$ and $55.37 \%$ lower than original for $5 \%, 10 \%$ and $15 \%$ hexane, respectively. However, it is intereting that, there is less significant change in wax deposition prevention after adding more hexane higher from $5 \%$ concentration at $45^{\circ} \mathrm{C}$. It can be concluded that for hexane the preferred hexane concentration can be $10 \%$ because the pour-point reduction and high wax prevention. This condition is the important data to apply hexane for wax deposition prevention in the practical work for the future.

\subsection{Effect of MEA on wax deposition}

Figure 3 illustrates the results of the effect of MEA for wax deposition by using MEA from $2500 \mathrm{ppm}$ to 7500 ppm and temperature from from $25{ }^{\circ} \mathrm{C}$ to $45^{\circ} \mathrm{C}$. From the results, MEA has no effect on pour-point reduction because the pour-point temperature at different MEA concentrations does not change. Nevertheless, for wax deposition, the figure shows that adding more MEA or applying higher temperature can reduce the amount of wax deposition. At $25^{\circ} \mathrm{C}$, the wax deposit can be reduced to $79.36 \%, 80.76 \%$ and $83.02 \%$ for MEA concentration at 2500,5000 and $7500 \mathrm{ppm}$, respectively. Also, $45^{\circ} \mathrm{C}$, the amount of wax is reduced to $39.19 \%, 57.44 \%$ and $63.84 \%$ at 2500,5000 and 7500 ppm, respectively.

\subsection{Effect of PMAO on wax deposition}

PMAO is a wax crystal modifier. The addition of PMAO in crude oil also has less effect on pour-point reduction. On the other hand, as shown in Figure 4, PMAO has ability to reduce wax deposition. At $25^{\circ} \mathrm{C}$, the amount of wax can be reduced for $74.52 \%, 78.25 \%$ and $88.51 \%$ for PMAO at 2500, 5000 and 7500 ppm, respectively. The amount of wax is reduced less with higher temperature from $58.54 \%$ to $75.41 \%$ at $45{ }^{\circ} \mathrm{C}$. In term of the effect of temperature, It also can be seen clearly 
that an increase in temperature from $25{ }^{\circ} \mathrm{C}$ to $45^{\circ} \mathrm{C}$ can decrease the amount of wax deposit to $89.61 \%$ for original oil and for $83.09 \%, 81.24 \%$ and $77.77 \%$ at 2500 , 5000 and $7500 \mathrm{ppm}$, respectively. Therefore, temperature has more effect on wax deposition.

\subsection{Comparison of Wax Inhibitors}

The performance of wax inhibitors can be compared based on the pour-point reduction as well as the amount of wax deposit. From the results of pour-point reduction, it is obvious that hexane is the only one can reduced pour-point temperature effectively for $19.55 \%$ compared to original oil. However, for wax deposition prevention, it also performs well up to $92.56 \%$ reduction. However, the effective amount of hexane used is comparatively higher than other inhibitors. Based on this result, the suitable concentration is $10 \%$ of hexane for both pour-point reduction and the amount of wax deposit applications.

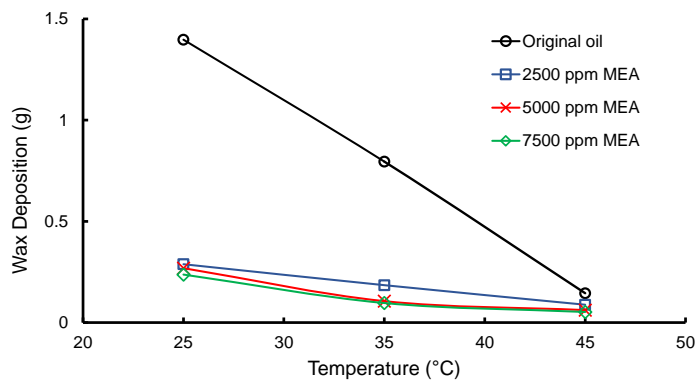

Fig 3. Result of MEA concentration on wax deposition.

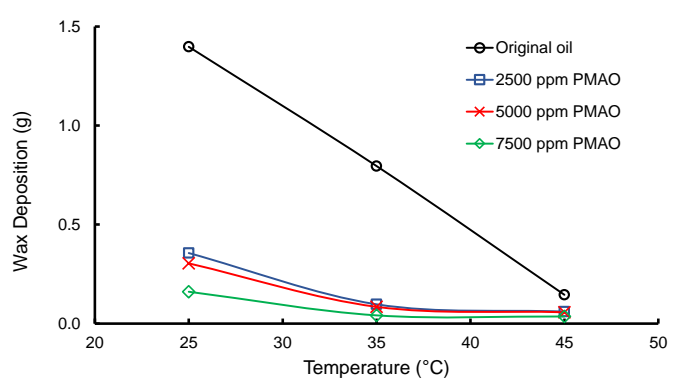

Fig 4. Result of PMAO concentration on wax deposition.

Like MEA, PMAO has less effect on pour point reduction and it is not reported here. On the contrary, both inhobitors have very good performance on wax deposition prevention. Wax deposit can be lowered with the higher concentration especially at low temperature. However, at higher temperature, the concentration of inhibitors has less effect because wax can be formed less. The percentage of wax reduction can range from $39.19 \%$ to $83.02 \%$ for MEA and from $58.54 \%$ to $88.51 \%$ for PMAO at the same conditions. From these results, it can be concluded that PMAO has higher performance than that of MEA at the same conditions. Also, the working concentration of PMAO can be $7500 \mathrm{ppm}$ at low temperature or $5000 \mathrm{ppm}$ for higher temperature.

\section{Conclusions}

In petroleum indusstry, waxy crude oil can be formed and it can cause more problems for oil production. The technology selected to remove the wax problem is the chemical method with 3 inhibitors, hexane, Poly(maleic anhydride-alt-1-octadecene) (PMAO) and monoethanolamine (MEA). In this study, the performance of wax inhibitor are assessed by the measurement of pour-point reduction and wax deposition prevention of crude oil from Mae Soon area, Fang oilfield. Wax deposition is determined by cold finger method. The wax inhibitors are combined in oil sample at various concentrations from $5 \%$ to $15 \%$ for hexane and from $2500 \mathrm{ppm}$ to $7500 \mathrm{ppm}$ for both MEA and PMAO. From the result, it is shown that hexane is used effectively to reduce pour-point temperature up to $19.55 \%$ and wax deposition up to $92.56 \%$ reduction. Furthermore, MEA and PMAO have less effect on pourpoint reduction but have high efficiency on wax deposition prevention. Between them, PMAO can offer the better wax deposition prevention performance than MEA especially at low temperature and high concentration. The amount of wax deposit is less at the same conditions. The percentage of wax deposit is reduced from from $39.19 \%$ to $83.02 \%$ for MEA and from $58.54 \%$ to $88.51 \%$ for PMAO at the same conditions. Moreover, based on the results, the working concentration of hexane can be at $10 \%$ and PMAO can be $7500 \mathrm{ppm}$ at low temperature or $5000 \mathrm{ppm}$ for higher temperature. This can be applied to the real field in Mae Soon area in Fang oilfield to reduce the wax problem in the future.

\section{Acknowledgments}

The authors would like to gratefully acknowledge the Malaysia-Thailand Joint Authority (MTJA) for financial support of this project.

\section{References}

1. H.M. Min, Evaluation of wax deposition prevention for crude oil production from Mae Soon oilfield, Master Thesis, Chulalongkorn University, Bangkok, Thailand (2018)

2. O. Juntarasakul, K. Maneeintr, IOP Conf. Ser.: Earth Environ. Sci. 140 (2018)

3. A. Japper-Jaafara, P.T. Bhaskorob, Z.S. Miorc, Pet. Sci. Eng. 147, 672 (2016)

4. A. Hosseinipoura, A.B. Japper-Jaafarb, S. Yusupa S, Procedia Engineering. 148, 1022 (2016)

5. K. Fan, Q. Huang, S. Li, D. Zhao, SPE 176447-MS (2015)

6. M.A. Theyab, J Sci. 2, 112 (2018)

7. H.M. Min, K. Manintr, IOP Conf. Ser.: Earth Environ. Sci. 268 (2019)

8. A.T.T. Aye, Correlation development of wax deposition prediction from Fang oilfield, Master 
Thesis, Chulalongkorn University, Bangkok, Thailand (2020)

9. K. Maneeintr, J. Jiravivitpanya, T. Meekoch, T. Boonpramote, IOP Conf. Ser.: Mater. Sci. Eng. 842 (2020)

10. American Society for Testing and Materials (ASTM) Standard Test Method for Pour Point of Crude Oils (2006)

11. Y. Chi, N. Daraboina, C. Sarica, Energy \& Fuels 31, 4915 (2017)

12. N. Ridzuan, F. Adam, Z. Yaacob, Orient. J. Chem. 31, 1999 (2015) 